\title{
Short Communication: Empirical and Mechanistic Evidence for the Role of Pyridoxal-5'-Phosphate in the Generation of Methanethiol from Methionine
}

\author{
D. D. Wolle, ${ }^{\star}$ D. S. Banavara, $†$ and S. A. Rankin ${ }^{\star 1}$ \\ *Department of Food Science, University of Wisconsin, Madison 53706 \\ †Mead Johnson Nutritionals, Evansville, IN 47721
}

\section{ABSTRACT}

The catabolism of the sulfur-containing AA Met to form flavor-active volatile sulfur compounds (VSC) is an important mechanism in flavor development during cheese maturation. Numerous enzymes catalyzing AA catabolism require the presence of the cofactor pyridoxal-5'-phosphate (PLP). In fact, reports have shown that some of these reactions can be catalyzed by PLP alone, albeit at a reduced rate. We hypothesized that, as a specific application in cheese flavor reactions, PLP can react directly with free Met to generate a specific VSC, methanethiol (MTH). In this study, the ability of PLP to catalyze MTH generation from Met was examined under "cheeselike" conditions of salt and $\mathrm{pH}$. Methionine and varying concentrations of PLP were incubated in a buffer (pH $5.2+4.0 \% \mathrm{NaCl}$ ) analogous to the aqueous phase of aged Cheddar cheese. Samples were analyzed using headspace solid-phase microextraction, and relative concentrations of VSC were determined by gas chromatography-mass spectrometry. Results showed MTH, dimethyl disulfide, and dimethyl trisulfide production when Met and PLP were incubated together at $7^{\circ} \mathrm{C}$ (cheese-aging temperature). These results indicate that the production of VSC from Met can occur nonenzymatically as catalyzed by free PLP.

Key words: aroma, cheese flavor, methionine, amino acid catabolism

During the ripening process in cheese, lactic acid bacteria catabolize AA to form a wide array of flavor-active compounds. In particular, the catabolism of Met generates volatile sulfur compounds (VSC), which are major components of cheese flavor (McSweeney, 2004). Such VSC include methanethiol (MTH), methional, dimethyl disulfide (DMDS), and dimethyl trisulfide (DMTS). Two main enzymatic pathways are thought to be re-

Received May 23, 2006.

Accepted June 23, 2006.

${ }^{1}$ Corresponding author: sarankin@wisc.edu sponsible for VSC production in cheese (Figure 1). The aminotransferase pathway is initiated by a transaminase, which catalyzes the transfer of the Met amino group to an $\alpha$-keto acid acceptor, usually $\alpha$-ketoglutarate, producing glutamate and $\alpha$-keto-4-(methylthio)butanoic acid. $\alpha$-Keto-4-(methylthio)-butanoic acid is in turn converted to MTH by both chemical and enzymatic steps (Smit, et al., 2005). In the alternate lyase pathway, cystathione- $\beta$-lyase, cystathione- $\gamma$-lyase (CGL) and Met- $\gamma$-lyase (MGL) catalyze the direct enzymatic cleavage of the $\gamma$-sulfur-carbon bond of Met to form MTH. In both pathways, MTH is converted to DMDS, then to DMTS, via oxidation (Figure 2; Rankin, et al. 2006). Cystathione- $\beta$-lyase and CGL catalyze steps in the synthesis of Met and Cys, respectively, but can also catabolize these AA to generate VSC (Alting, et al., 1995; Bruinenburg, et al., 1997), whereas the role of MGL appears to be strictly catabolic. Methionine- $\gamma$ lyase is of particular interest to researchers studying cheese-aging mechanisms, because it was shown to possess substantial VSC-generating activity under cheeselike $\mathrm{pH}$, temperature, and salt conditions (Dias and Weimer, 1998). Increasing the rate of VSC production is one proposed mechanism of accelerating the cheeseaging process. However, the wide array of microbes involved in cheese aging and the varying effects on their metabolic systems from $\mathrm{pH}$; temperature; and substrate, cofactor, and enzyme concentrations (Alting, et al., 1995; Bruinenburg, et al., 1997; Gao et al., 1998; Smacchi and Gobetti, 1998; Seefeldt and Weimer, 2000) make the predictable control of VSC production difficult. A strictly chemical method of VSC production may have value in promoting controlled VSC production in cheese.

One candidate for enhancing VSC production in cheese is pyridoxal-5'-phosphate (PLP), a common cofactor in AA metabolic pathways (Hemme, 1982) that is one of 2 biologically active vitamin forms of the $\mathrm{B}_{6}$ family (Heyl et al., 1951; Figure 3). Pyridoxal-5'-phosphate is the predominant $B_{6}$ form in foods, whereas pyridoxamine-5'-phosphate (PMP), the other biologically active vitamin form, is found at lower levels (Orr, 


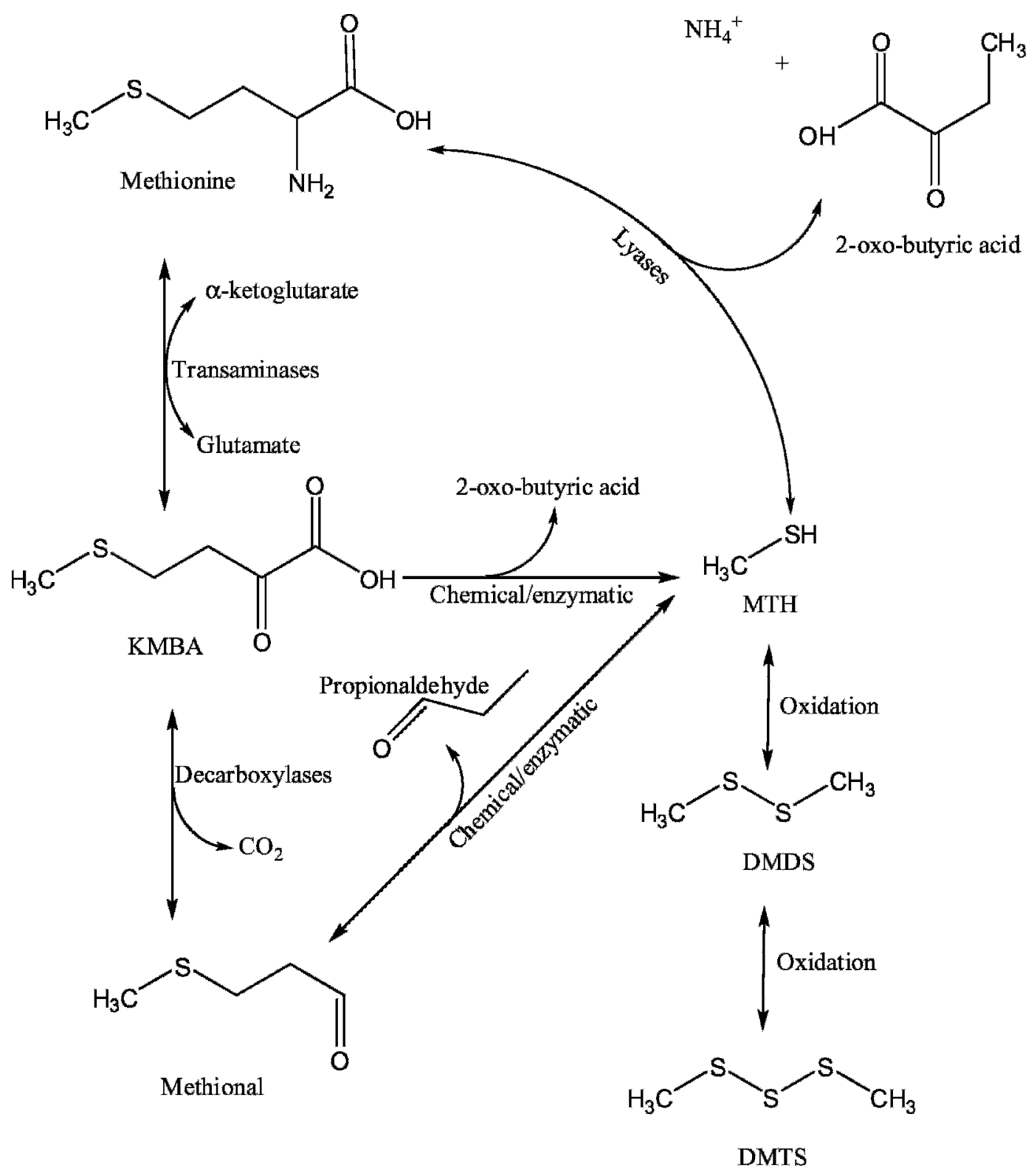

Figure 1. Enzymatic and chemical conversion of Met to volatile sulfur compounds (adapted from Smit et al., 2005; reproduced with permission from Blackwell Publishing, 2006). KMBA = $\alpha$-keto-4-(methylthio)-butanoic acid; MTH = methanethiol; DMDS = dimethyl disulfide; DMTS = dimethyl trisulfide.

1969). Pyridoxal-5'-phosphate and PMP are interconverted during transaminase-catalyzed amino group transfer (Eliot and Kirsch, 2004). In addition, the different $\mathrm{B}_{6}$ vitamin forms readily gain or lose a phosphate group because of the activity of phosphatases (Coburn and Whyte, 1988).

Pyridoxal-5'-phosphate is a required participant in many AA biosynthetic and catabolic reactions and is a coenzyme in both the aminotransferase and lyase pathways of VSC production from Met. It has long been known that both pyridoxal and PLP are capable of cata- lyzing AA catabolism in the absence of enzyme, although at a reduced rate and with decreased specificity (Snell, 1985). One example is the lyase mechanism, in which a labile oxygen or sulfur bond to the AA $\beta$ - or $\gamma$ carbon is cleaved. Metzler and Snell (1952) showed that the lyase-type reaction occurred when either Ser or Cys was incubated with pyridoxal and an aluminum salt at $100^{\circ} \mathrm{F}$ and $\mathrm{pH}$ 5.0. Serine was converted to pyruvate and ammonia, whereas Cys was converted to hydrogen sulfide, pyruvate, and ammonia. The existence of a similar reaction between Met and PLP was of particular 


\section{$\mathrm{CH}_{3} \mathrm{SH} \rightleftharpoons \mathrm{CH}_{3} \mathrm{~S}^{-}+\mathrm{H}^{+}$ MTH \\ $\mathrm{CH}_{3} \mathrm{~S}^{-}$

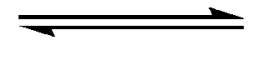 \\ $\mathrm{CH}_{3} \mathrm{~S}^{*}+\mathrm{e}^{-}$
$\mathrm{CH}_{3} \mathrm{~S}^{*}+\mathrm{CH}_{3} \mathrm{~S}^{*} \rightleftharpoons \mathrm{CH}_{3} \mathrm{~S}-\mathrm{SCH}_{3}$ DMDS \\ $\mathrm{CH}_{3} \mathrm{~S}-\mathrm{SCH}_{3}+\mathrm{e}^{-} \rightleftharpoons \mathrm{CH}_{3} \mathrm{~S}_{-} \mathrm{S}^{-}+\mathrm{CH}_{3}^{+}$
$\mathrm{CH}_{3} \mathrm{~S}-\mathrm{S}^{-}+\mathrm{CH}_{3} \mathrm{~S}^{*} \rightleftharpoons \mathrm{CH}_{3} \mathrm{~S}-\mathrm{S}-\mathrm{S}-\mathrm{CH}_{3}$ DMTS

Figure 2. Chemical interconversions of methanethiol (adapted from Rankin et al., 2006). MTH = methanethiol; DMDS = dimethyl disulfide; DMTS = dimethyl trisulfide.

interest in this study, because cleavage of the Met $\gamma$-sulfur-carbon bond produces MTH, and ultimately DMDS and DMTS (Figures 1 and 2). In potential application to cheese flavor research, this work explored whether PLP could generate VSC from Met under "cheeselike" conditions of temperature, $\mathrm{pH}$, and salt concentration, thereby providing a chemical alternative to the enzymatic reaction catalyzed by microbial lyases.

Assay mixtures of $5 \mathrm{~mL}$ total volume were placed in 8-mL glass serum vials. Each vial contained $50 \mathrm{mM}$ phosphate buffer, $\mathrm{pH} 5.2,4 \% \mathrm{NaCl}$ (wt/vol), and $10 \mathrm{mM}$ Met ( $>98 \%$ purity; Sigma Chemical Co., St. Louis, MO). The Met was added as $500 \mu \mathrm{L}$ of a $100 \mathrm{mM}$ stock solution in deionized water. Assay vials also contained either none, 1, or $2 \mu M$ PLP (98\% purity; MP Biomedicals, Solon, $\mathrm{OH} ; 10$ or $20 \mu \mathrm{L}$ of a $2.5 \mathrm{~m} M$ stock solution in deionized water). All assays were created in triplicate.
The reagent and buffer solutions used were sterile-filtered, and assay vials and pipette tips were autoclaved before use. Vials were sealed with Teflon-lined septa, wrapped in aluminum foil to minimize PLP photodecomposition, vortexed to mix, and incubated at $7^{\circ} \mathrm{C}$ for $30 \mathrm{~d}$. At 5 -d intervals, samples were mixed by vortexing and placed in a $37^{\circ} \mathrm{C}$ block heater for $10 \mathrm{~min}$. The headspace of each vial was then assayed for volatile compounds by solid-phase microextraction (SPME) gas chromatography-mass spectrometry. After each SPME sampling, the septum was replaced and the vial was immediately returned to the $7^{\circ} \mathrm{C}$ incubator. An SPME fiber (85 $\mu M$ carboxen/polydimethylsiloxane; Supelco Co., Bellefonte, PA) was introduced into the headspace of each vial for $10 \mathrm{~min}$ at $37^{\circ} \mathrm{C}$ to absorb volatiles. The fiber was then desorbed at $250^{\circ} \mathrm{C}$ into the injection port of the gas chromatograph (model 6890; Agilent Co., Wilmington, DE). The column (Rtx-Wax, $30 \mathrm{~m}, 0.25$ $\mathrm{mm}$ i.d., $0.5 \mu \mathrm{m}$ stationary phase; Restek Inc., Bellefonte, PA) temperature program used was as follows: $35^{\circ} \mathrm{C}$ initial temperature for $2 \mathrm{~min}$, an increase of $5^{\circ} \mathrm{C}$ per min up to $70^{\circ} \mathrm{C}$, an increase of $20^{\circ} \mathrm{C}$ per min up to $200^{\circ} \mathrm{C}$, and hold for 5 min. Quantitation of the VSC peak areas was achieved by integration of the mass spectrometry signal (model 5973 mass analyzer; Agilent Co.) using the selected ion monitoring mode $(\mathrm{m} / z 48$ for MTH, $m / z 94$ for DMDS, $m / z 104$ for methional, and $\mathrm{m} / z 126$ for DMTS). The addition of $1 \mathrm{ppm}$ of furfuryl alcohol (98\% solution, 99\% purity; Sigma Chemical Co.) to all assays as an internal standard allowed the calculation of relative VSC peak areas. The concentration of DMDS in nanomoles was calculated from comparison of the total VSC area units to a DMDS standard curve generated by adding 0 to $0.5 \mathrm{nmol}$ of DMDS (98\% purity; Sigma Chemical Co.) to septum sealed assay vials containing $5 \mathrm{~mL}$ of buffer and sampling headspaces for the aforementioned VSC.

Detectable levels of DMDS (limit of detection for DMDS was $0.010 \mathrm{nmol}$ ) were found in assay vial head-

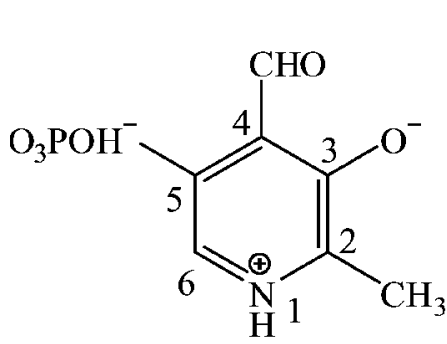

PLP

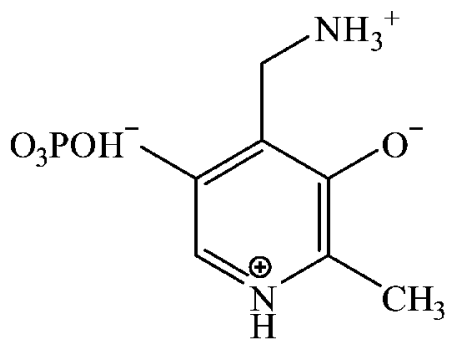

PMP

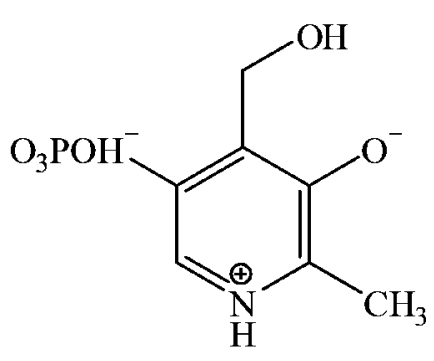

PNP

Figure 3. Phosphorylated forms of vitamin $\mathrm{B}_{6}$. The charge structures shown predominate at $\mathrm{pH} 5.2$ (Kallen, et al. 1985). PLP = pyridoxal5'-phosphate; PMP = pyridoxamine-5'-phosphate; $\mathrm{PNP}=$ pyridoxine-5' - phosphate. 


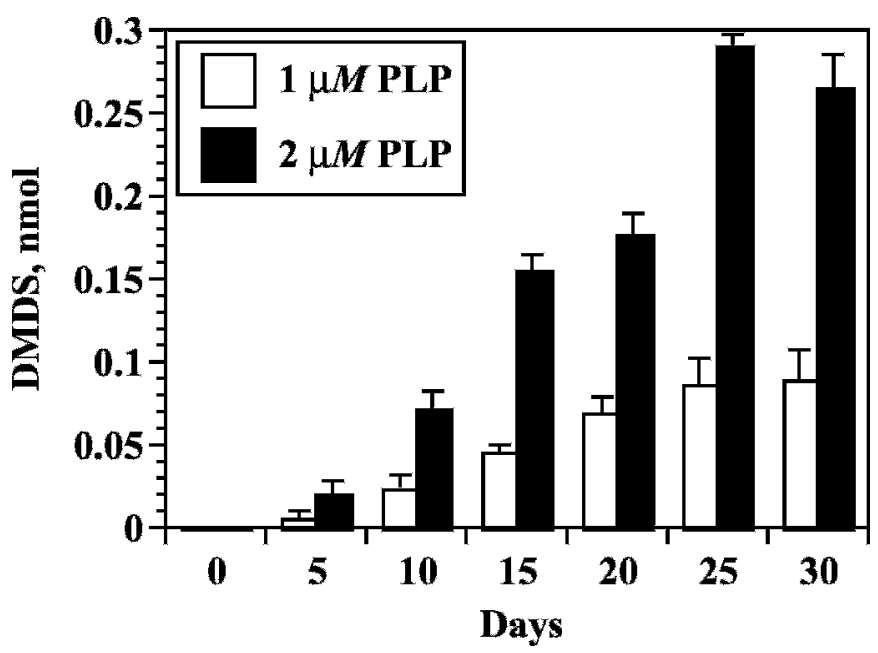

Figure 4. Generation of volatile sulfur compounds (VSC) from Met, in the presence of pyridoxal-5'-phosphate (PLP). Aluminum foilwrapped, 8-mL stoppered serum vials contained $5 \mathrm{~mL}$ of $50 \mathrm{mM}$ phosphate buffer, $\mathrm{pH} 5.2,4 \%$ (wt/vol) $\mathrm{NaCl}, 10 \mathrm{~m} M$ Met, and either 1 or $2 \mu M$ PLP. Vials were incubated at $7^{\circ} \mathrm{C}$ for the time periods indicated, then analyzed for VSC by gas chromatography-mass spectrometry. Data points are averages of triplicate samples. DMDS = dimethyl disulfide. Error bars represent 1 standard deviation.

spaces by the fifth day of incubation at $7^{\circ} \mathrm{C}$ (Figure 4). By d 30, MTH and DMTS had also reached low but measurable levels, whereas no methional was detected during the time course of these assays. Methanethiol, DMDS, and DMTS undergo facile interconversion under the assay conditions used, with DMDS being the predominant species $(>99.99 \%)$. Figure 4 shows that DMDS concentrations generally increased with time $(P$ $<0.001$ ) and were dependent on the PLP concentration $(P<0.001)$, with VSC levels roughly tripling as the PLP concentration was doubled. A time $\times$ PLP concentration interaction exists $(P<0.001)$, as shown in Figure 4 for the different slopes of DMDS over time and the declining slopes of both PLP concentrations at the later times. Control assays lacking PLP did not generate detectable VSC over the entire time course of the assay. These data suggest that PLP is a promising candidate for the chemical enhancement of VSC production, especially because it is a water-soluble vitamin and a generally recognized as safe (GRAS) compound when supplemented to a justifiable level.

In Figure 5, a possible mechanism for the production of VSC from Met and PLP is examined. This mechanism can be considered a nonenzymatic analog of the lyase reactions catalyzed by cystathione- $\beta$-lyase, CGL and MGL. A lyase mechanism was more likely than a transaminase mechanism because of the absence of amino group acceptors in the assay system (Figure 1). As in PLP-dependent enzyme-catalyzed reactions, the conju- gated double bond system of the PLP-AA adduct acts as an electron sink, stabilizing carbanions formed on the AA backbone when stable leaving groups $\left(\mathrm{CO}_{2}\right.$, $\mathrm{NH}_{4}{ }^{+}, \mathrm{OH}^{-}, \mathrm{CH}_{3} \mathrm{~S}^{-}$) are removed. The interaction of PLP with Met is initiated by the formation of a Schiff base between the AA $\alpha$-amino group and the PLP carbonyl group (step 1). If a proton is then removed from the Met $\alpha$-carbon (step 2), the resonance structure formed can be reprotonated, moving the carbon-nitrogen double bond to the other side of the Met $\alpha$-carbon (step 3). The repositioned double bond would stabilize a carbanion formed at the Met $\beta$-carbon by deprotonation (step 4). This stabilized carbanion could drive rearrangement of the local electronic structure, cleaving the carbonsulfur bond and forming a double bond between the $\beta$ and $\gamma$-carbons. In enzymatic systems, the $\beta-\gamma$-carbon double bond is reduced and the carbon-nitrogen double bond is hydrolyzed to form 2-oxo-butyric acid and PMP (Figure 1); the PMP is then converted to PLP with the release of free ammonia (Eliot and Kirsch, 2004). However, the fate of the adduct formed in this nonenzymatic reaction by carbon-sulfur bond cleavage and MTH release is presently unknown.

The question of how much endogenous PLP is available in cheese to specifically support VSC production is difficult to answer. Pyridoxal-5'-phosphate concentrations in milk have been measured at $\sim 1 \mu M$ (Coburn et al., 1992; Argoudelis, 1997), whereas in Cheddar cheese a value of $0.074 \mathrm{mg} / 100 \mathrm{~g}$ of cheese (equivalent to $\sim 3 \mu M$ in the cheese aqueous phase) was reported (ARS-USDA Nutrient Data Laboratory, 2006). Thermal treatment of food decreases $\mathrm{B}_{6}$ levels. In particular, vat pasteurization causes $\mathrm{B}_{6}$ losses of up to $70 \%$ (Woodring and Storvick, 1960), converting some of the PLP to PMP (Bernhart et al., 1960). In animals, PLP is usually bound via a Schiff base to protein lysyl residues (Li et al., 1974). This adduct allows the transport of PLP to specific tissues (Lumeng, et al., 1985), protects the cofactor phosphate group from hydrolysis, and increases PLP reactivity during enzyme-catalyzed processes (Walsh, 1977). Protein-PLP complexes may therefore trap substantial quantities of endogenous cofactor in the cheese matrix, despite its high water solubility.

Increasing available PLP levels in cheese may increase VSC production from Met. However, several factors complicate this process. Being relatively watersoluble, most PLP would partition into the whey if added to milk prior to coagulation, suggesting application as a powder or solution to the curd mass postcoagulation. Studies in our lab have indicated that a roughly $1,000 \times$ increase in VSC production occurs when the reaction temperature is raised from 7 to $37^{\circ} \mathrm{C}(\mathrm{D}$. Wolle, unpublished data). This enhancement at elevated temperatures may have application in enzyme-modified 
<smiles></smiles>

PLP<smiles></smiles>

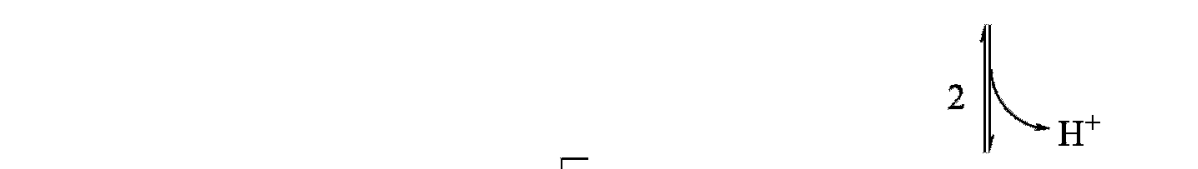

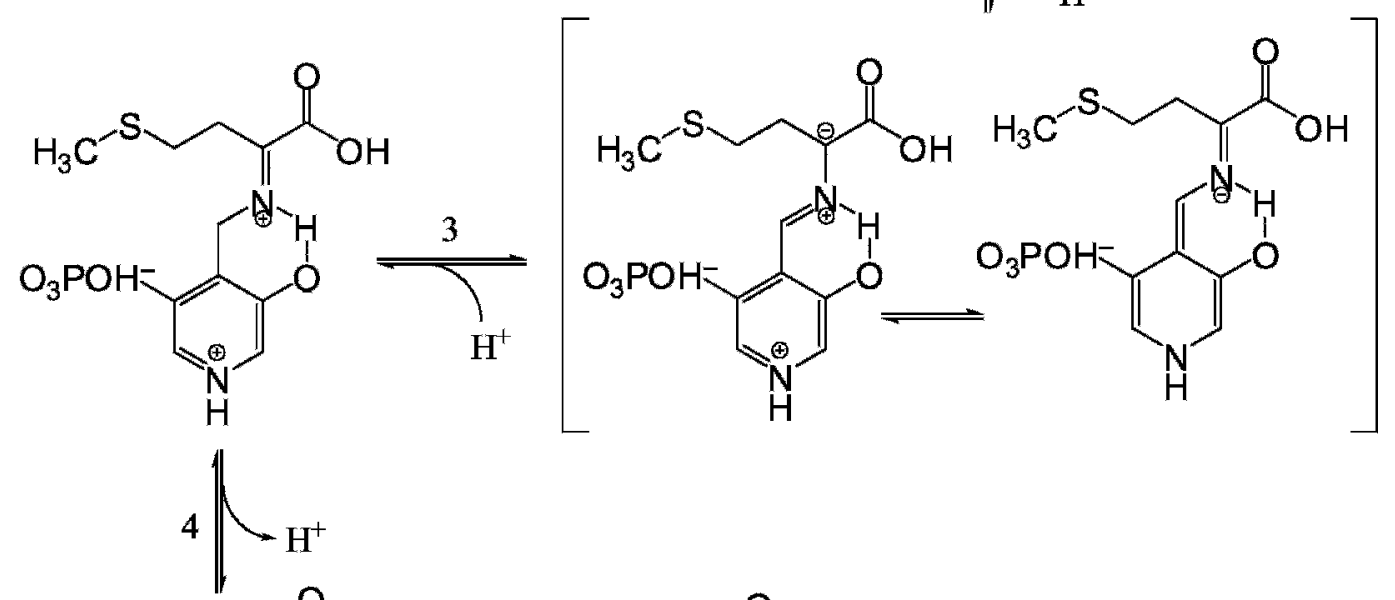<smiles></smiles><smiles>CCCCCCSC</smiles><smiles></smiles>

Figure 5. Pyridoxal-5'-phosphate (PLP)-catalyzed degradation of Met. The reaction sequence shown is for a lyase-type mechanism. $\mathrm{MTH}=$ methanethiol. 
cheese production, where higher temperatures and shorter incubation times are utilized.

Whether PLP acts in a truly catalytic fashion to convert Met to VSC is presently unknown. It is possible that PLP is consumed during turnover, either by being trapped in an intermediate adduct form (Figure 5, step 5) or (in the absence of an amino group acceptor) by conversion to PMP. In addition, PLP stability under the assay conditions used has not been examined. If the free cofactor is reasonably stable and is able to act as a chemical catalyst without being consumed, then it is far more useful as an enhancer of VSC production in cheese.

Adjunct cultures used in enzyme-modified cheese slurries are often highly proteolytic; hence, larger amounts of free Met would be available to react with the added PLP. Of course, other free AA would also be present in high concentrations and may be decarboxylated or deaminated by PLP, whereas Met, Cys, Ser, and Thr are all potential substrates for lyase-type reactions. The enhanced catabolism of branched-chain and aromatic AA are of particular concern, because they are known to produce a number of flavor-active compounds (McSweeney, 2004). However, the data obtained in this study are sufficiently promising to warrant additional experiments to study the effect of PLP augmentation on flavor generation in cheeses.

\section{REFERENCES}

Alting, A. C., W. J. Engels, S. Schalkwijk, and F. A. Exterkate. 1995. Purification and characterization of cystathione $\beta$-lyase from $L a c$ tococcus lactis subsp. cremoris B78 and its possible role in flavor development in cheese. Appl. Environ. Microbiol. 61:4037-4043.

Argoudelis, C. J. 1997. Simple high-performance liquid chromatographic method for the determination of all seven vitamin $\mathrm{B}_{6^{-}}$ related compounds. J. Chromatogr. 790:83-91.

ARS-USDA Nutrient Data Laboratory. 2006. USDA National Nutrient Database for Standard Reference, Release 18. http://www. nal.usda.gov/fnic/foodcomp/Data/SR18/reports/sr18page.htm Accessed May 5, 2006.

Bernhart, F. W., E. D'Amato, and R. M. Tomarell. 1960. The vitamin $\mathrm{B}_{6}$ activity of heat-sterilized milk. Arch. Biochem. Biophys. 88:267-269

Bruinenberg, P. G., G. De Roo, and G. K. Limsowtin. 1997. Purification and characterization of cystathione $\gamma$-lyase from Lactococcus lactis subsp. cremoris SK11: Possible role in flavor compound formation during cheese maturation. Appl. Environ. Microbiol. 63:561-566.

Coburn, S. P., J. D. Mahuren, T. A. Pauly, K. L. Ericson, and D. W. Townsend. 1992. Alkaline phosphatase activity and pyridoxal phosphate concentrations in the milk of various species. J. Nutr. 122:2348-2353.
Coburn, S. P., and M. P. Whyte. 1988. Role of phosphatases in the regulation of vitamin $\mathrm{B}_{6}$ metabolism in hypophosphatasia and other disorders. Pages 65-93 in Clinical and Physiological Applications of Vitamin $\mathrm{B}_{6}$. J. E. Leklem and R. D. Reynolds, ed. Alan R. Liss, New York, NY.

Dias, B., and B. Weimer. 1998. Purification and characterization of L-methionine $\gamma$-lyase from Brevibacterium linens BL2. Appl. Environ. Microbiol. 64:3327-3331.

Eliot, A. C., and J. F. Kirsch. 2004. Pyridoxal phosphate enzymes: Mechanistic, structural, and evolutionary considerations. Annu. Rev. Biochem. 73:383-415.

Gao, S., E. S. Mooberry, and J. L. Steele. 1998. Use of ${ }^{13} \mathrm{C}$ nuclear magnetic resonance and gas chromatography to examine methionine catabolism by lactococci. Appl. Environ. Microbiol. 64:4670-4675.

Hemme, D. 1982. Microbiological catabolism of amino acids during cheese ripening. Sci. Aliments 2:113-123.

Heyl, D., E. Luz, S. A. Harris, and K. Folkers. 1951. Phosphates of the vitamin $\mathrm{B}_{6}$ group. I. The structure of codecarboxylase. J. Am. Chem. Soc. 73:3430-3433.

Kallen, R. G., T. Korpela, A. E. Martell, Y. Matsushima, C. M. Metzler, D. E. Metzler, Y. V. Morozov, I. M. Ralston, F. A. Savin, Y. M. Torchinsky, and H. Ueno. 1985. Chemical and spectroscopic properties of pyridoxal and pyradoxamine phosphates. Pages 38-98 in Transaminases. P. Christen and D. E. Metzler, ed. John Wiley \& Sons, New York, NY.

Li, T. K., L. Lumeng, and R. L. Vetch. 1974. Regulation of pyridoxal 5'phosphate metabolism in liver. Biochem. Biophys. Res. Commun. 61:627-634.

Lumeng, L., T.-K. Li, and A. Lui. 1985. The interorgan transport and metabolism of vitamin $\mathrm{B}_{6}$. Pages $35-54$ in Vitamin $\mathrm{B}_{6}$ : Its Role in Health and Disease. R. D. Reynolds and J. E. Leklem ed. Alan R. Liss, New York, NY.

McSweeney, P. L. 2004. Biochemistry of cheese ripening. Int. J. Dairy Technol. 57:127-144.

Metzler, D. E., and E. E. Snell. 1952. Deamination of serine: I. Catalytic deamination of serine and cysteine by pyridoxal and metal salts. J. Biol. Chem. 198:353-361.

Orr, M. L. 1969. Pantothenic acid, vitamin $B_{6}$ and vitamin $B_{12}$ in foods. Home Economics Research Report No. 36. ARS-USDA, Washington, DC.

Rankin, S. A., and D. S. Banavara, E. S. Mooberry, J. L. Steele, J. R. Broadbent, and J. E. Hughes. 2006. Volatile sulfur-containing compounds from methionine metabolism in genetically modified Lactobacillus helveticus CNRZ32 strains. In Flavor of Dairy Foods, American Chemical Society Symposium Series, American Chemical Society, Washington, DC.

Seefeldt, K. E., and B. C. Weimer. 2000. Diversity of sulfur compound production in lactic acid bacteria. J. Dairy Res. 83:2740-2746.

Smacchi, E., and M. Gobetti. 1998. Purification and characterization of cystathione $\gamma$-lyase from Lactobacillus fermentum DT41. FEMS Microbiol. Lett. 166:197-202.

Smit, G., B. A. Smit, and W. J. M. Engels. 2005. Flavor formation by lactic acid bacteria and biochemical flavor profiling of cheese products. FEMS Microbiol. Rev. 29:591-610.

Snell, E. E. 1985. Pyridoxal phosphate in nonenzymatic and enzymatic reactions. Pages 19-35 in Transaminases. P. Christen and D. E. Metzler, ed. John Wiley \& Sons, New York, NY.

Walsh, C. T. 1977. Enzymatic Reaction Mechanisms. Freeman Press, San Francisco, CA.

Woodring, M. J., and C. A. Storvick. 1960. Vitamin B ${ }_{6}$ in milk: Review of literature. J. Assoc. Off. Agric. Chem. 43:63-80. 